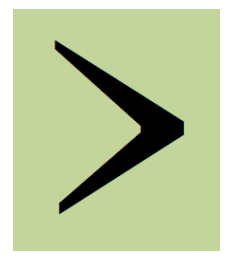

Papers in Historical Phonology

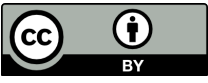

http://journals.ed.ac.uk/pihph ISSN 2399-6714

Licensed under a

Creative

Volume 4, 1-21 (2019)

DOI: $10.2218 /$ pihph.4.2019.3014

Commons 4.0

International

License

\title{
One rule, two frequency effects
}

\author{
Marjoleine Sloos \\ Fryske Akademy \\ (KNAW, Royal Netherlands Academy of Arts and Sciences)
}

\begin{abstract}
The low-mid unrounded front vowel /ع:/ in German (as in Bären) has been subject to change since Old High German. It slowly merged with the high-mid unrounded front vowel /e:/, but a reversal seems to have emerged recently. This paper investigates both historical and current change of the BÄREN vowel. Historical change is investigated through literature-based research; current change is examined through corpusbased research. This paper takes the approach of studying both grammatical context and frequency of use. The two major insights of this study are (i) that the BÄREN vowel has been subject to change for a long time and is still variable, and (ii) that frequency effects interact with grammar in an unexpected way. This interaction shows us how to proceed with hybrid grammar-lexicon modelling and I advocate a combined model of Optimality Theory and Exemplar Theory to account for this type of grammar-frequency interactions.
\end{abstract}

\section{Background}

The low-mid unrounded front vowel / $\varepsilon$ : / in German (henceforth the BÄREN vowel) occurs as an underlying form in words such as Bär 'bear' or Ähre 'ear of corn', or as the result of umlaut. Examples of words featuring this vowel are given in the second column in (1), (derived through umlaut from the bases in the first column).

$\begin{array}{llll}\text { (1) Jahr } & \text { 'year' } & \text { zweijährig } & \text { 'two years (old)' } \\ \text { Bahn } & \text { 'train, tram' } & \text { Bähnchen } & \text { 'rail.DiminUTIVE' } \\ \text { Schwager } & \text { 'brother-in-law' } & \text { Schwägerin } & \text { 'sister-in-law' } \\ \text { Bad } & \text { 'bath' } & \text { Bäder } & \text { 'bath.PLURAL' } \\ \text { gab } & \text { 'give.PAST' } & \text { gäbe } & \text { 'give.SuBJUNCTIVE' } \\ \text { fahr } & \text { 'drive' } & \text { fährst } & \text { 'drive.2SINGULAR' }\end{array}$


From the ninth century onward, umlaut of long $<a>$ is orthographically indicated in texts (Iverson \& Salmons 1996). The graphical diacritic itself does not provide any indication for the precise pronunciation in Old High German of course, but we can be sure that the pronunciation of the BÄREN vowel differed from the high-mid unrounded front vowel (henceforth the BEEREN vowel) since in poetry <ä> never rhymes with <e > (Voyles 1992, 171). In addition, Wiesinger $(1970,356)$ analyses this $<$ ä $>$ in Old High German as an extreme open vowel.

After Old High German, a long period of gradual merger of the BÄREN and BEEREN vowels set in. Whereas the mid-high front unrounded BEEREN vowel seems quite stable across the German speaking area, this is very different for the BäREN vowel. The use of <ä> in spelling increased between 1350 and 1700 (Moser et al. 1988, 220) but decreased afterwards (Moser et al. 1988, 150). It is unclear, however, whether the use of the grapheme <ä> was descriptive or prescriptive. The only inference we can make is that it shows variation. This variation reached its highest point probably in the 18th century. Tritschler (1913) collected original observations from the 18th century about the pronunciation of the BÄREN vowel. This includes examples is which <ä> is pronounced as [e:] and also the reverse case, where $<\mathrm{e}>$ is pronounced as [ $\left.\varepsilon^{\mathrm{x}}\right]$. Some sources mention a clear distinction between the BÄREN and BEEREN vowels; others mention that these sounds were merged. Regional variation may play a role in the variety of observations (see also section 2). All this means that the gradual merger of the BÄREN and BEEREN vowels spanned centuries and was far from complete in the 18th century. The BÄREN and BEEREN vowels were not even fully merged at the beginning of the 20th century when Viëtor (1909) predicted that the merger would be completed by the end of the 20th century - a prediction that was not borne out, as we will see in the remainder of this article.

A factor that is often found to correlate with language variation and change is lexical frequency. Two main types of frequency effects have been claimed to exist in language change: either high-frequency words change first or low-frequency words change first. High-frequency words change first in reduction processes (including assimilation and lenition) (Hooper 1976, Phillips 1984, Phillips 2006). This reducing effect occurs because high-frequency words are subject to automation processes more than low-frequency words. In case of paradigmatic change without reduction, low frequency words change first and high-frequency words tend to be conserved (like strong verbs in Germanic languages - see Lieberman et al. 2007). Such conserving effects are explained by the relatively strong mental representations of high-frequency words, which make it more difficult for them to undergo change. Usually, either conserving effects or reducing effects are observed in language change. 
This seems logical, since either high-frequency words change first or low-frequency words change first. However, in the present article, we observe that both types of frequency effects occur simultaneously in the variation that exists in the BÄREN vowel in current Standard German. These two patterns appear to closely interact with the phonological rule of pre- $r$ vowel lowering. I argue that this observation shows us how to proceed with the (hybrid) modelling of frequency and grammar.

I suspect that variation of the types that I describe here reflects ongoing sound change, in line with the sources mentioned above, and hence we should expect not only frequency effects but also a difference in pronunciation between younger and older speakers, and between males and females, as have often been observed in ongoing sound change (see, for example, Labov 2001). Since the rhotic in Standard German has been observed to lower the BäREN vowel (König 1989, Sloos 2013a), we take this context into account as well.

This article is organized as follows. The next section describes the data and the analysis. Section 3 describes the results. Section 4 features discussion, and the article concludes in section 5 .

\section{Methodology}

The present study uses data from the corpus Deutsch Heute 'German Today'. Section 2.1 describes the corpus and the selection of the data. Section 2.2 describes the vowel measuring and normalization procedure.

\subsection{The Corpus 'German Today'}

The data used in this article are selected from the corpus, Deutsch Heute 'German Today', collected by the Institut für Deutsche Sprache (IDS) in Mannheim (Brinckmann et al. 2008). The recordings of the corpus were made between 2006 and 2009. The corpus contains data of spoken Standard German from more than 160 locations, spread over Germany and other European countries where German is one of the official languages. In eighty-five locations, four students from a local secondary school were recorded: two female speakers and two male speakers, aged between seventeen and twenty. In addition, recordings of one female and one male speaker aged between fifty and sixty were collected. In another eighty places, only four secondary school students took part in the project. Since I am interested in change, I selected the locations in which both younger and older speakers were recorded. The final selection contained 71 locations for which two older and four younger speakers were recorded in Germany only. Since I am interested in informal speech, I only used the biographical interviews for my investigation (leaving the read speech parts to future investigation). Each interview lasted for 30- 
45 minutes, and per speaker from two to over sixty realizations of the BÄREN vowel were analysed. In general, vowel length is unambiguous, except in Städte 'town.PLURAL' and nächst 'next' (Mangold 1994), which can be realised with either a long or a short mid-low front vowel. Therefore, words with these stems were excluded from the analysis. In sum, I analysed 6192 BäREN vowels.

\subsection{Vowel measuring and normalization procedure}

To compare the pronunciation of the BäREN vowels, their pronunciation had to be quantified in a unified way. The vowels [e:] and [ $\left.\varepsilon^{*}\right]$ mainly differ from each other by their height, viz. [e:] is higher than [ $\varepsilon:]$. A small difference in frontness also occurs: [e:] is slightly more front than [ $\left.\varepsilon^{\prime}\right]$. Differences in the high-low dimension are reflected in the first formant (F1) of the vowels, whereas differences in the front-back dimension correspond to the value of the second formant (F2). See the vowel diagram in Figure 1.

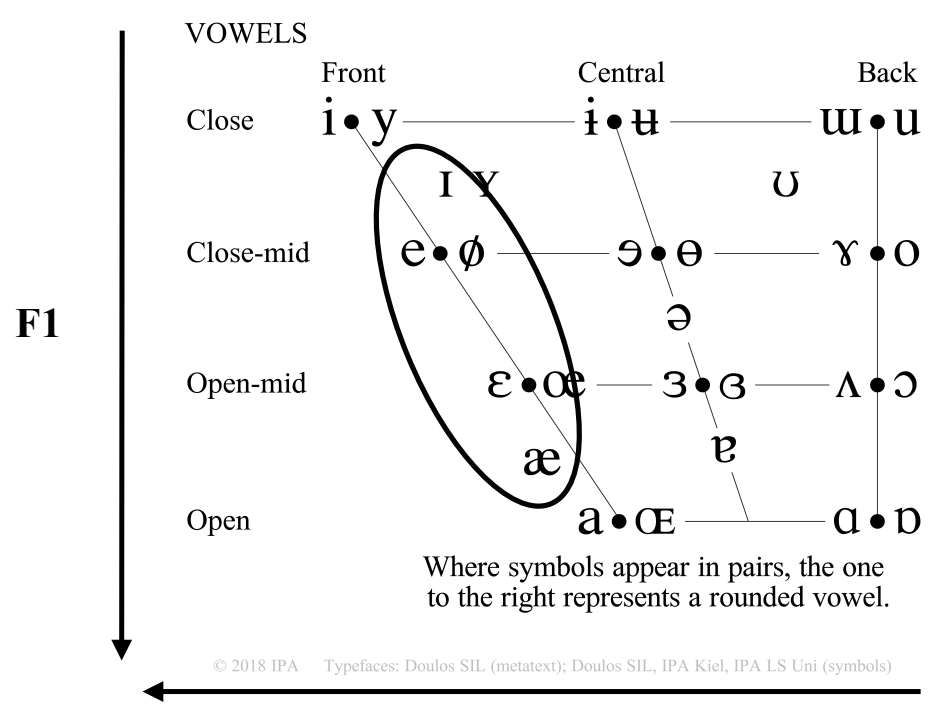

F2

Figure 1: Vowel diagram of the International Phonetic Alphabet; the added ellipse indicates the possible pronunciations of the BÄREN vowel. ${ }^{1}$

Praat speech processing software (Boersma \& Weenink 2010) was used for the analysis. The target vowel onsets and offsets were manually segmented. Formant tracks were automatically computed using the Burg

1 IPA Chart, http://www.internationalphoneticassociation.org/content/ipa-chart, available under a Creative Commons Attribution-Sharealike 3.0 Unported License. Copyright (C) 2018 International Phonetic Association. 
LPC algorithm in Praat. Since the vowels that were measured almost always had a clear steady state (i.e., stable F1 and F2) - that is, they were truly monophthongs - it sufficed to measure the temporal midpoint of the vowels. This temporal midpoint was measured using a Praat script.

As is standard procedure in vowel measurements, the F1 and F2 were Bark-transformed in order to arrive at perceptually normalized values (Traunmüller 1990). Different models have been developed for vowel normalization (see Adank 2003 for an overview). However, since the variation under discussion is rather straightforward (involving just variation between $\left[\varepsilon_{i}\right]$ and [e:]), I followed a simple procedure that interpolates the vowel under discussion just between the lowest and the highest front vowel per speaker, as proposed by van Heuven at al. (2005) and van Bezooijen \& van Heuven (2010) (see also Escudero at al. 2009 for the implementation of this procedure). Therefore, for each speaker in the corpus, 3-5 realizations of these reference vowels, i.e., the highest vowel /i: / (before a high, i.e., velar consonant) and the lowest vowel /a:/ (before an $-r$ ) were measured. The most extreme F1 and F2 of these reference vowels were taken as the beginning and end points of the subjects' maximal vowel height dimension (to arrive at the maximal vowel space of each speaker). Consequently, the location of the realization of the BÄREN and the BEEREN vowels was expressed as the placement on a relative scale between 0 (corresponding to [a:]) and 100 (corresponding to $[\mathrm{i}]$ ]). This interpolation was computed by dividing the Euclidian distance between the target vowel and the /a:/ reference $\operatorname{vowel}(\Delta \mathrm{a})$ by the Euclidian distance between both reference vowels, i.e., the two endpoints of the scale $(\Delta \mathrm{b})$, multiplied by $100(2)$.

(2) Computation of the Euclidian distance and the interpolation of the mid front vowels (van Bezooijen \& van Heuven 2010)

$$
\begin{aligned}
& \Delta \mathrm{a}=\sqrt{ }\left[\left(\operatorname{BarkF1}\left(\varepsilon^{\prime}\right)-\operatorname{BarkF1}(\mathrm{a}:)\right)^{2}+(\operatorname{BarkF} 2(\varepsilon:)-\operatorname{BarkF} 2(\mathrm{a}:))^{2}\right] \\
& \left.\left.\Delta \mathrm{b}=\sqrt{[}[(\text { BarkF1(i: })-\text { BarkF1(a:) })^{2}+(\text { BarkF2(i: })-\text { BarkF2(a:) }\right)^{2}\right] \\
& \text { Interpolated } \varepsilon:=(\Delta \mathrm{a} / \Delta \mathrm{b})^{*} 100 \text {. }
\end{aligned}
$$

By this interpolation of the vowels between [i] and [a] for each speaker, I obtained a speaker-normalized value for each realization of the BÄREN vowels.

\section{Results}

As frequently observed (Eichinger 2000, Eichinger 2006, Spiekermann 2008 amongst others), Standard German is far from homogeneous. Geographical variation patterns may be related to the local dialectal pronunciation, larger dialect groups (or: regiolects), and nationalects 
(Clyne 1992). This is also relevant for the BÄREN vowel. For example, the BÄREN vowel used to be distinctive from the BEEREN vowel but is currently undergoing merger in Swiss Standard German; on the other hand, the BäREN vowel was merged with the BEEREN vowel Austrian Standard German and is currently undergoing reversal (Sloos 2013b, 2018). The BÄREN vowel in Germany shows a distinction that is often stylistic: the BÄREN vowel is low in highly formal speech and merged with the BEEREN vowel elsewhere. The present paper limits the analysis to the variation of the BÄREN vowel in Standard German as spoken in Germany. The data are not representative for local dialectal influences because of a limited number of locations investigated, but they are for the main traditional dialect groups: Low Saxon, East Low German, West Middle German, East Middle German, High Franconian, Swabian-Alemannic, and AustroBavarian (see Figure 2).

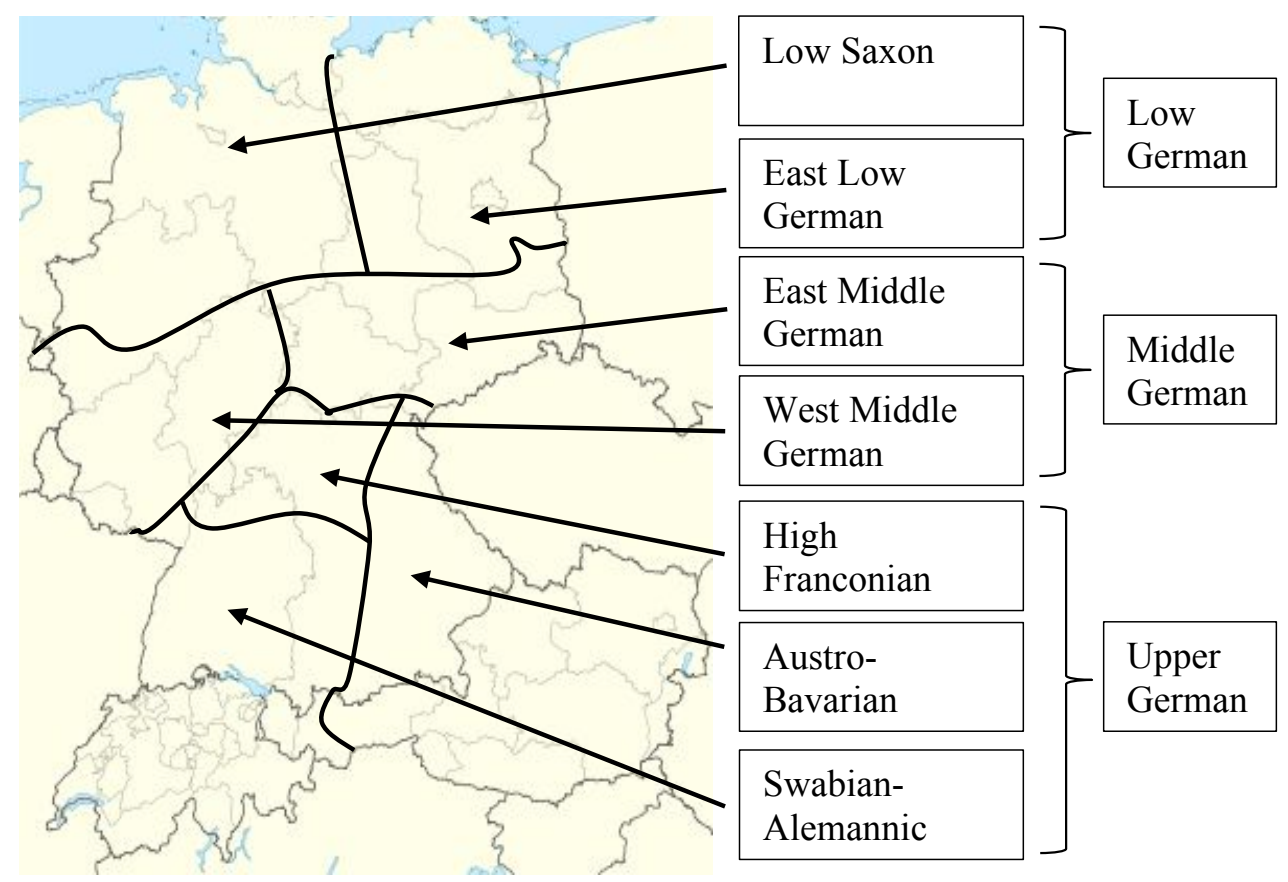

Figure 2: Main dialect divisions of German: Low German consists of Low Saxon and East Low German; Middle German is divided into West Middle German and East Middle German; and Upper German is separated into High Franconian, Swabian-Alemannic, and Austro-Bavarian (Adam 1989)

For each regiolect, I conducted a linear regression test in R statistical environment (R Core Development Team, 2017), with the interpolated vowel as the dependent variable and age group, gender, frequency, and pre- $r$ context as independent variables. I used model comparison and present the models with the best fits based on the AIC below. I computed 
lemma frequency, since lemma frequency is often found to be a better predictor for frequency effects than token frequency (Jescheniak \& Levelt 1994, Gahl 2008). The lemma is the set of words which have the same stem, and lemma frequency consists of the summed frequency of all tokens of a lemma. Lemma frequency cannot be computed as usual in this study, since the BÄREN vowel often occurs as umlaut of $/ a /$, as in Bad Bäder 'bath.Singular PluRAL'. Since the frequency of Bad is not likely to influence the pronunciation of Bäder, and vice versa, the words with $<a>$ are not included in the lemma frequency count. Besides, the BÄREN vowel occurs frequently in a particular suffix, namely -ität (a deadverbial nominalizer). Therefore, I treated -ität as a lemma itself, and summed the frequency of all words which are suffixed with -ität.

Let us now turn toward the results of the regression test for Low Saxon, West Middle German and Swabian-Alemannic. In Low Saxon, we observe a strong effect of pre- $r$ vowel lowering $(t=-12.06, p<0.001)$. The negative estimate indicates that the pre- $r$ context correlates with more lowering of the BäREN vowel. We also observe a frequency effect $(t=4.64, p<0.001)$, showing that higher frequency correlates with higher vowels, although the effect size of pre- $r$ vowel lowering is much stronger than that of the frequency effect (compare the estimates of -15.42 vs. 0.008). Moreover, pre- $r$ vowel lowering and frequency show an interaction $(t=-5.27, p<0.001)$, see Table 1 . Similar patterns are shown for West Middle German (Table 2) and Swabian-Alemannic (Table 3).

\begin{tabular}{l|c|c} 
Random effects & Variance & S.D. \\
\hline Recording (Intercept) & 40 & 6.3 \\
\hline Residual & 193 & 13.9 \\
\hline
\end{tabular}

Number of obs: 1714, groups: Interview, 99

Fixed effects

\begin{tabular}{l|c|c|c|c} 
& Est. & S.E. & t-value & p-value \\
\hline (Intercept) & 75.52 & 1.017 & 74.28 & $<0.001^{*}$ \\
\hline rContext & -15.42 & 1.278 & -12.06 & $<0.001^{*}$ \\
\hline LemmaFrequency & 0.008 & 0.002 & 4.64 & $<0.001^{*}$ \\
\hline rContext:LemmaFreq & -0.010 & 0.002 & -5.27 & $<0.001^{*}$
\end{tabular}

Table 1: Mixed-effects model for Low Saxon 


\section{Random effects}

\begin{tabular}{l|c|c} 
& Variance & S.D. \\
\hline Recording (Intercept) & 81 & 9.04 \\
\hline Residual & 231 & 15.2 \\
\hline
\end{tabular}

Number of obs: 1221, groups: Interview, 70

Fixed effects

\begin{tabular}{l|c|c|c|c} 
& Est. & S.E. & t-value & p-value \\
\hline (Intercept) & 66.673 & 1.481 & 45.03 & $<0.001^{*}$ \\
\hline rContext & -7.983 & 1.637 & -4.88 & $<0.001^{*}$ \\
\hline LemmaFrequency & 0.008 & 0.002 & 3.41 & $<0.001^{*}$ \\
\hline rContext:LemmaFreq & -0.010 & 0.002 & -4.07 & $<0.001^{*}$
\end{tabular}

Table 2: Mixed-effects model for West Middle German

\section{Random effects}

\begin{tabular}{l|c|c} 
& Variance & S.D. \\
\hline Recording (Intercept) & 118 & 10.9 \\
\hline Residual & 190 & 13.8
\end{tabular}

Number of obs: 627, groups: Interview, 44

\section{Fixed effects}

\begin{tabular}{l|c|c|c|c} 
& Est. & S.E. & t-value & p-value \\
\hline (Intercept) & 65.04 & 2.124 & 30.6 & $<0.001^{*}$ \\
\hline rContext & -5.53 & 2.260 & -2.45 & $<0.001^{*}$ \\
\hline LemmaFrequency & 0.008 & 0.003 & 2.72 & $<0.001^{*}$ \\
\hline rContext:LemmaFreq & -0.013 & 0.003 & -3.89 & $<0.001^{*}$
\end{tabular}

Table 3: Mixed-effects model for Swabian-Alemannic

East Middle German shows a slightly different pattern. Whereas this variety also shows a strong lowering effect of pre- $r$ context $(t=-6.66$, $p<0.001)$, frequency is negatively correlated to vowel height $(t=-3.62$, $p<0.001$ ), showing that higher frequency correlates to a lower vowel. There is also an interaction between pre- $r$ vowel lowering and frequency $(t=-5.48, p<0.001)$ (Table 4). 


\section{Random effects}

\begin{tabular}{l|c|c} 
& Variance & S.D. \\
\hline Recording (Intercept) & 114 & 10.6 \\
\hline Residual & 212 & 14.5 \\
\hline
\end{tabular}

Number of obs: 933, groups: Recording, 50

Fixed effects

\begin{tabular}{l|c|c|c|c} 
& Est. & S.E. & t-value & p-value \\
\hline (Intercept) & -70.0 & 1.894 & 36.99 & $<0.001^{*}$ \\
\hline rContext & -11.6 & 1.754 & -6.66 & $<0.001^{*}$ \\
\hline LemmaFrequency & -0.009 & 0.003 & -3.62 & $<0.001^{*}$ \\
\hline rContext:LemmaFreq & -0.015 & 0.004 & -5.48 & $<0.001^{*}$
\end{tabular}

Table 4: Mixed-effects model for East Middle German

Frequency effects are not significant main factors in all regiolects; for instance in East Low German, we only find an effect of pre- $r$ vowel lowering $(t=-10.12, p<0.001)$ (Table 5). In Austro-Bavarian, pre- $r$ vowel lowering is not a significant factor, but frequency is $(t=3.513, p<$ $0.001)$. This frequency effect does interact with pre- $r$ vowel lowering $(t=-4.055, p<0.001)$ (Table 6).

\section{Random effects}

\begin{tabular}{l|c|c} 
& Variance & S.D. \\
\hline Recording (Intercept) & 130 & 1.4 \\
\hline Residual & 217 & 14.7 \\
\hline
\end{tabular}

Number of obs: 500, groups: Interview, 35

Fixed effects

\begin{tabular}{l|c|c|c|c} 
& Est. & S.E. & t-value & p-value \\
\hline (Intercept) & 79.95 & 2.470 & 32.37 & $<0.001^{*}$ \\
\hline rContext & -26.73 & 2.640 & -10.12 & $<0.001^{*}$ \\
\hline LemmaFrequency & 0.000 & 0.000 & 0.340 & 0.999 \\
\hline rContext:LemmaFreq & 0.000 & 0.000 & -0.060 & 0.999
\end{tabular}

Table 5: Mixed-effects model for East Low German 


\section{Random effects}

\begin{tabular}{l|c|c} 
& Variance & S.D. \\
\hline Recording (Intercept) & 81 & 9.0 \\
\hline Residual & 231 & 15.2
\end{tabular}

Number of obs: 628, groups: Interview, 41

Fixed effects

\begin{tabular}{l|c|c|c|c} 
& Est. & S.E. & t-value & p-value \\
\hline (Intercept) & 73.63 & 2.521 & 29.209 & $<0.001^{*}$ \\
\hline gender-male & -6.706 & 3.163 & -2.120 & $0.034^{*}$ \\
\hline rContext & 1.724 & 2.415 & 0.714 & 0.476 \\
\hline LemmaFrequency & 0.011 & 0.003 & 3.513 & $0.001^{*}$ \\
\hline rContext:LemmaFreq & -0.013 & 0.003 & -4.055 & $<0.001^{*}$
\end{tabular}

Table 6: Mixed-effects model for Austro-Bavarian

At this point we have to note that these frequency effects are indicative for sound change and we would expect to find age effects as well. However, we observe age effects only in High Franconian $(t=-3.35$, $p=0.001$ ), where younger speakers were more likely to use a lower vowel (Table 7).

\section{Random effects}

\begin{tabular}{l|c|c} 
& Variance & S.D. \\
\hline Recording (Intercept) & 69 & 8.3 \\
\hline Residual & 225 & 15.0 \\
\hline
\end{tabular}

Number of obs: 570, groups: Interview, 35

\section{Fixed effects}

\begin{tabular}{l|c|c|c|c} 
& Est. & S.E. & t-value & p-value \\
\hline (Intercept) & 74.2 & 2.998 & 24.7 & $<0.001^{*}$ \\
\hline age: younger & -11.2 & 3.343 & -3.35 & $0.001^{*}$ \\
\hline rContext & -8.40 & 2.371 & -3.54 & $<0.001^{*}$ \\
\hline LemmaFrequency & 0.012 & 0.003 & 3.69 & $<0.001^{*}$ \\
\hline rContext:LemmaFreq & -0.014 & 0.004 & -4.04 & $<0.001^{*}$
\end{tabular}

Table 7: Mixed-effects model for High Franconian 
In sum, the strongest predictor for the pronunciation of the BÄREN vowel turns out to be pre- $r$ context in almost all regiolects. The vowel is generally pronounced lower (that is, more [ع:]-like) before an /ь/ and higher (that is, more [e:]-like) before other segments. Interestingly, an implicational relationship exists: if a main effect of frequency occurs, there is also an interaction of frequency with pre- $r$ context. In all cases, the estimates of the interactions are negative. This indicates that higher frequency leads to more vowel lowering in pre- $r$ context, as expected. But the way in which the interaction works out in non-pre- $r$ context is not immediately clear. To understand this interaction better, I performed a classification test.

Figure 3 shows the classification tree for East Middle German. It makes significant binary splits in the data set and thus provides insight into (i) the relative importance of the independent variables; (ii) the interaction between factors; and (iii) the distribution of vowel height within all classifications (Tagliamonte \& Baayen 2012). The relative importance of factors is shown by the ranking of the leaves: the higher in the tree, the more important the factor is. The interaction of the factors is shown by the branches. The distribution of vowel height is shown by the box plots on the bottom of the plot. Figure 3 shows that the main predictor, indicated by the highest node [1], is pre- $r$ context (as would be expected based on the results discussed above). The interaction between frequency and pre- $r$ vowel lowering is shown by the branching. In pre- $r$ context [node 9], words with lower frequency, here $\leq 341$ [node 10], have a higher mean pronunciation; and words with higher frequency, here $>341$ [node 11], have a lower pronunciation. The distribution of the interpolated vowel in these categories is shown in the boxplots. In nonpre- $r$ context, the relation between frequency and vowel height is reversed. Words with lower frequency, here $\leq 619$ [node 7], have a relatively lower mean pronunciation and words with higher frequency, here $>619$ [node 8], have a relatively higher pronunciation.

In each variety where frequency effects are found we observe the same pattern: lower vowels are more likely to occur in high-frequency words in pre-r context; and higher vowels are more likely to occur in high-frequency words in non-pre- $r$ context.

Note that the gender and age effects in Figure 3 were not significant in the regression model; the classification test overanalyses the data somewhat. But the tendency of age effects in Figure 3 shows the same direction as in High Franconian, where it is significant: younger speakers tend to use lower vowels. I discuss this in the next section. 


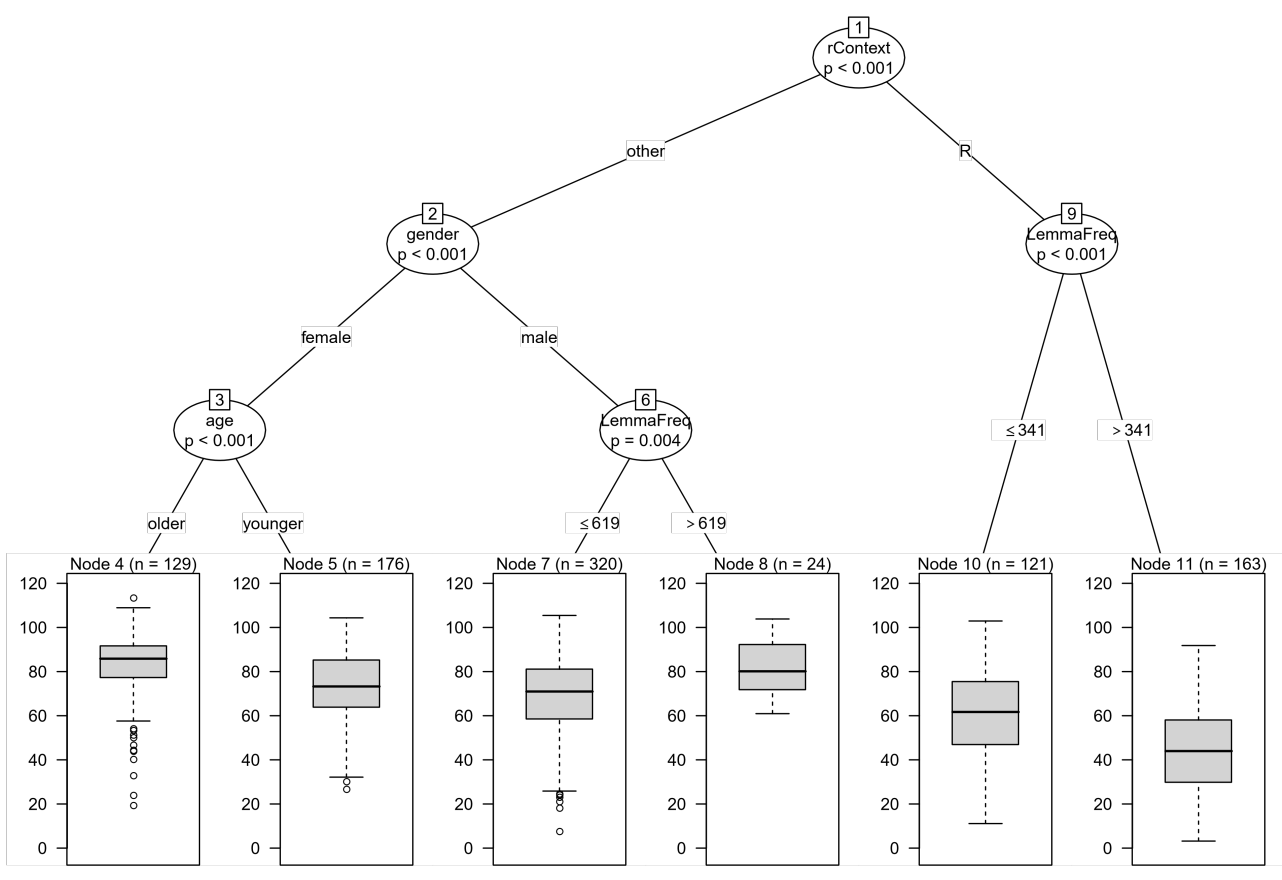

Figure 3: Classification tree for East Middle German, showing a conserving effect in non-pre- $r$ context and a reducing effect in pre- $r$ context

\section{Discussion}

I investigated the variation of the BäREN vowel in Standard German in all main dialect regions. The BÄREN vowel seemed highly sensitive to lowering in pre- $r$ context and showed two different frequency effects, which are interconnected with pre- $r$ vowel lowering. Pre- $r$ vowel lowering affects the BÄREN vowel of high-frequency words first: this frequency effect is usually observed in cases of reduction and assimilation (see also section 1) in language change. The lowering effect in pre- $r$ context can be attributed to the phonological feature [+low] of the rhotic that follows the BÄREN vowel. This feature becomes apparent in the allophonic alternation of the rhotic in German: it surfaces as a consonant in onsets but as a vowel in coda position (Hall 1993, Wiese $2000)$. The consonantal realization is usually a voiced uvular [в] and the vocalized realization is described as a low central vowel [e].2 Although in the Sound Pattern of English (SPE), uvulars are specified as [-high, -low] (Chomsky \& Halle 1968, 307), later studies showed that uvulars must be specified for [+low] (see van de Weijer 1994, 120-121) for an overview). The vocalized alternant $[\mathrm{e}]$ undoubtedly has the feature [+low]. In some German varieties, like in Swiss Standard German, the rhotic is an alveolar

${ }^{2}$ See also Hall (1997), where the vocalized alternant is transcribed as $[\Lambda]$. 
trill [r], in which case lowering is not expected. Actually, in Swiss Standard German, the contrast between the BÄrEN vowel and the BEEREN vowel was preserved over time but is currently showing a merger, in which the BÄREN vowel is raised. According to Sloos (2018), this is due to convergence with Northern Standard German, which is regarded as the prestige variety among young Swiss speakers, who also have a rather negative attitude towards their own variety. In the data from Germany, discussed in the present paper, trills are not observed.

If in pre- $r$ context the BÄREN vowel lowers, this is due to assimilation, hence high-frequency words change first. But in non-pre- $r$ context, the lowering effect cannot occur. Hence, we observe the opposite pattern in which low-frequency words are more likely to be pronounced with a midlow vowel and high-frequency words are more likely to be pronounced with a mid-high vowel. This is the pattern that is usually observed in analogical change. That is, we simultaneously observe two frequency effects in the lowering of the BÄREN vowel: high-frequency words change first in pre- $r$ context and low-frequency words change first in non-pre- $r$ context.

This study shows how a grammar-frequency interaction may look like in detail: a rule has a certain context in which it applies and other contexts in which it does not apply, and frequency effects may differ according to these contexts. This points towards the need for the hybrid modelling of grammar and frequency effects. This kind of modelling itself is not new, but detailed information as to how grammar and frequency interact, as in the variation of the BëREN vowel, may show us in more detail how to construct this model. Such interactions are not often reported, but are observed in e.g., van de Weijer et al. (2013) and Sloos (2013a). This could work along the lines explored below.

Pre- $r$ vowel lowering is a phonological rule which can be expressed in Optimality Theory (Prince \& Smolensky 1993). I illustrate the minigrammar of speakers who distinguish the BÄREN vowel from the BEEREN vowel, and who adopt pre- $r$ vowel lowering for the BÄREN vowel but not for the BEEREN vowel. ${ }^{3}$ Although the BÄREN vowel and the BEEREN vowel have merged to a great extent, language users are able to tell the difference in the lexical sets, by the distinction that exist in certain dialects or in highly formal speech (Mangold 1994), in spelling (Sloos 2013b), or by morphological relations, such as an underlying /a:/ in the base. I adopt the markedness constraint ${ }^{*} \varepsilon$, , as in (3).

$$
{ }^{*} \varepsilon \text { : }
$$

Assign a violation mark to any occurrence of [ $[\varepsilon$ :].

3 Other grammars are possible, but I cannot discuss them all in detail here. With minor alternations in the order of the constraints (EVAL), these grammars can be derived. 
This constraint is motivated by the fact that in German, lax vowels are generally short and tense vowels are usually long (Wiese 2000). The vowel / $\varepsilon$ : / is an exception to this pattern and thus relatively marked.

The phonological rule of pre- $r$ vowel lowering is captured by a highranked constraint that prohibits a mid-high vowel followed by an / $/$.

*V[mid-high]ь

Assign a violation mark to each sequence of a mid-high vowel followed by an $[$ в].

To prevent lowering of the BEEREN vowel, I invoke IDENT-e:.

(5) IDENT-e:

Assign a violation mark to any vowel that does not correspond to an underlying /e:/.

(6) Tableaux for (high-frequency) BÄREN vowels:

Bären 'bears' and Dänen 'Danes'

\begin{tabular}{|c||c|c|c|}
\hline /be:sen/ & IDENT-e: & ${ }^{*}$ V[mid-high]ь & ${ }^{*} \varepsilon:$ \\
\hline \hline be:sen & & $* !$ & \\
\hline be:sen & & & $*$ \\
\hline
\end{tabular}

\begin{tabular}{|c||l|l|l|}
\hline /dernen/ & IDENT-e: & $*$ V[mid-high]ь & ${ }^{*} \varepsilon:$ \\
\hline \hline dernen & & & \\
\hline dernen & & & $* !$ \\
\hline
\end{tabular}

Tableaux for BEEREN vowels:

Beeren 'berries' and denen 'they.GENITIVE'

\begin{tabular}{|c|c|c|c|}
\hline /be:вعn/ & IDENT-e: & *V[mid-high]ь & ${ }^{*} \varepsilon:$ \\
\hline be:sen & & * & \\
\hline be:ben & $* !$ & & $*$ \\
\hline
\end{tabular}

\begin{tabular}{|c||c|c|c|}
\hline /de:nen/ & IDENT-e: & $* \mathrm{~V}[$ mid-high]ь & ${ }^{*} \varepsilon:$ \\
\hline de:nen & & & \\
\hline de:nen & $* !$ & & $*$ \\
\hline
\end{tabular}


A generative account, as discussed here, accounts for the grammar; in this case, the phonological rule of pre- $r$ vowel lowering for the BÄREN vowel. But the results show that the variation in the pronunciation of the BÄREN vowel also involves frequency effects. To provide a fully-fledged account of the variation, we have to implement these in some way. This does not mean that the grammatical account as such is incomplete: its nature is categorical and the grammatical process is adequately accounted for. The variation that is not accounted for so far (i.e., the frequency effects) does not take place in the grammar but in the lexicon. ${ }^{4}$ I therefore propose to model the frequency effects in a usage-based framework like Exemplar Theory.

In Exemplar Theory (ET), each time a word is perceived, it is stored in the lexicon as an exemplar, based on similarity. That is, similar exemplars are stored in a single category, mainly based on words. Different categories are also connected to each other dependent on the degree of similarity and analogy (e.g., Goldinger 1996, Bybee 1999, Pierrehumbert 2001, Bybee 2010). Categories with many exemplars correspond to higher neural activation. Therefore, relatively high neural activation of high-frequency words inhibits change of the category; their mental representation is too strong and a few instances of a different form will not affect the category. This is the source of the conserving effect, which we observed in the BÄREN vowel in non-pre- $r$ context. Assimilation processes such as pre- $r$ vowel lowering behave as reduction processes (Phillips 2006). In reduction processes, automation of articulation (due to frequent production) drives the change (Bybee 2010). Therefore, the BÄREN vowel in a pre- $r$ context lowers, first as a result of phonetics, which is later phonologized (see also BermudezOtéro 2006 for the life-cycle of morphemes). These are perceived and stored as exemplars with the mid-low pronunciation. The more of these mid-low forms are stored as exemplars, the more likely the overall representation changes, by competitive pressure (see Hoekstra et al. 2018, among others). 'Overall representation' translates to the underlying form in generative phonological terms; that can be the abstraction (or the average or prototype) of the exemplar category. In an ET-OT hybrid, the constraints are to be understood as generalizations over the exemplar-based lexicon. Therefore, we used the constraint ${ }^{*} \varepsilon$ : (but not IDENT-E:) which emerges from the relatively few exemplars which contain [ع:] in German; *V[mid-high]ь arises from the alternation between [e:] in non-pre-r contexts and $[\varepsilon:]$ in pre-r contexts; IDENT-e: emerges from the generalization that no alternation occurs in the BEEREN

\footnotetext{
${ }^{4}$ Note that this is about the effects of word frequency and not the frequency of two variants of a single word, which is the subject of analysis in frameworks as Stochastic Grammar (Boersma 1998 et seq., and the work of Anttila \& Cho 1998).
} 
vowels due to a high phoneme frequency, for example (see also van de Weijer 2014 for this approach). The idea that generalization across exemplars lead to constraints is in line with from Bybee's (2007) proposal that grammar derives from the lexicon.

The two frequency effects observed here are indicative for language change. However, we hardly observe any age effects. I tentatively propose that language change is occurring, but - in line with the historical developments - it is proceeding extremely slowly. Given the long-term variation from Old High German till now, it is perhaps not surprising that an age effect between 18-20 year old speakers and 50-65 year old speakers is not strong enough to confirm sound change. Moreover, sound change is known to be extremely slow at the beginning and at the end. The pattern observed here would fit into the beginning of a reversal of the former merger in most varieties, as also observed in Austrian Standard German (Sloos 2013a,b, 2018). As such we only observe frequency effects and no age effects.

\section{Conclusion}

In this article, I have shown that the BÄREN vowel in Standard German has been subject to variation since Old High German. In Old High German it was a low vowel, but it gradually raised, and we now seem to be witnessing the early stage of a reversal. In this reversal, we have seen that two well-known frequency effects, which are usually observed in different patterns of variation and change, interact with pre- $r$ vowel lowering. In pre- $r$ context, the BÄREN vowel is more often lowered in high-frequency words; but in non-pre- $r$ context, the BÄREN vowel is more often lowered in low-frequency words. This may be attributed to the fact that pre- $r$ vowel lowering is an assimilation rule, and as such belongs with reduction processes, in which, typically, high-frequency words change first. In non-pre- $r$ contexts, no reduction occurs, and therefore we mostly observe the conservatory effect of more frequent words in that context. The frequency effects suggest language change, but only in one regiolect (out of seven) do we actually observe an effect of speaker age. I have tentatively proposed that the reason for this may be that the change is proceeding at a slow pace and the age window is too small to show a difference. To capture interactions between phonological rules and frequency effects, I have proposed a hybrid Optimality-Exemplar theoretical account. 


\section{Comments invited}

PiHPh relies on post-publication review of the papers that it publishes. If you have any comments on this piece, please add them to its comments site. You are encouraged to consult this site after reading the paper, as there may be comments from other readers there, and replies from the author. This paper's site is here:

https://doi.org/10.2218/pihph.4.2019.3014

\section{Acknowledgements}

This research was partially funded by the German Research Foundation (Deutsche Forschungsgemeinschaft, GRK DFG 1624/1). The data used in this article and their frequencies were provided to the author by the Institute for German Language (Institut für deutsche Sprache, Mannheim) which is gratefully acknowledged.

\section{Author contact details}

Marjoleine Sloos

Fryske Akademy, (KNAW, Royal Netherlands Academy of Arts and Sciences)

Doelestraat 8

8911 DX, Ljouwert

The Netherlands.

m.sloos@fryske-akademy.nl

\section{References}

Adam, Ingrid. 1989. Das Neue Duden-Lexikon [Das Neue Duden-Lexikon in 10 Bänden: rund 100000 Stichwörter, über 12500 meist farbige Abbildungen und Zeichnungen sowie Tabellen und Übersichten im Text, 120 farbige Karten]. Mannheim: Duden Verlag.

Adank, Patti. 2003. Vowel normalization: A perceptual-acoustic study of Dutch vowels. University of Nijmegen PhD dissertation.

Anttila, Arto \& Young-Mee Yu Cho. 1998. Variation and change in optimality theory. Lingua 104. 31-56.

Bezooijen, Renée van \& Vincent van Heuven. 2010. Avant-garde Dutch: a perceptual, acoustic and evaluational study. In D. R. Preston \& N. A. Niedzielski (eds.), A reader in sociophonetics, 357-378. New York: Walter de Gruyter. 
Bermúdez-Otero, Ricardo. 2006. Phonological change in optimality theory. In Keith Brown (ed.), Encyclopedia of language and linguistics second edition, volume 9, 497-505. Oxford: Elsevier.

Boersma, Paul. 1998. Functional phonology: formalizing the interactions between articulatory and perceptual drives. University of Amsterdam $\mathrm{PhD}$ dissertation.

Boersma, Paul \& David Weenink. 2010. Praat: Doing phonetics by computer. [computer program].

Brinckmann, Caren, Stefan Kleiner, Ralf Knöbl \& Nina Berend. 2008. German today: an areally extensive corpus of spoken standard German. Sixth International Conference on Language Resources and Evaluation, Marrakech, Marocco. 3185-3191.

Bybee, Joan. 1999. Usage-based phonology. Functionalism and Formalism in Linguistics. 211-242.

Bybee, Joan. 2001. Phonology and language use. Cambridge: Cambridge University Press.

Bybee, Joan. 2007. From usage to grammar: The mind's response to repetition. Language 82(4). 711-733.

Bybee, Joan. 2010. Language, usage and cognition. Cambridge: Cambridge University Press.

Chomsky, Noam \& Morris Halle. 1968. The sound pattern of English. New York: Harper \& Row.

Clyne, Michael. 1992. German as a pluricentric language. In: Michael Clyne (ed.) Pluricentric Languages: Differing Norms in Different Nations, 117-147. Berlin: de Gruyter.

Eichinger, Ludwig. 2000. Das Deutsche - Eine europäische Sprache am Beginn des 21. Jahrhunderts (No. Sprachreport 8). Mannheim: Institut für Deutsche Sprache.

Eichinger, Ludwig. 2006. Das deutsche als plurizentrische sprache betrachtet. EFNIL Annual Conference. Madrid.

Escudero, Paola, Paul Boersma, Andréia Schurt Rauber \&Ricardo A. H. Bion. 2009. A cross-dialect acoustic description of vowels: Brazilian and European Portuguese. Journal of the Acoustical Society of America, 126(3). 1379-1393.

Gahl, Susanne. 2008. Time and thyme are not homophones: The effect of lemma frequency on word durations in spontaneous speech. Language 84(3). 474-496.

Goldinger, Stephen. D. 1996. Words and voices: Episodic traces in spoken word identification and recognition memory. Journal of 
Experimental Psychology: Learning, Memory, and Cognition 22(5). 1166-1183.

Hall, Tracy A. 1993. The phonology of German /R/. Phonology 10(1). 83105.

Heuven, Vincent van, Renée van Bezooijen \& Loulou Edelman. 2005. Pronunciation of / $\varepsilon$ i/ in avant-garde Dutch: a cross-sex acoustic study. In M. Filppula, J. Klemola, M. Palander \& E. Penttila (eds.), Dialects across borders. 185-210. Amsterdam: John Benjamins.

Hoekstra, Eric, Anne Merkuur, Marjoleine Sloos \& Jeroen van de Weijer. 2018. Calculating a pattern's competitive strength: competition between $/ æ /$ and $/ \Lambda /$ in irregular simple pasts and past participles in English. The Mental Lexicon 13(1). 143-157.

Hooper, Joan. 1976. Word frequency in lexical diffusion and the source of morphophonological change. Current Progress in Historical Linguistics, 96-105.

Iverson, Gregory K. \& Joseph C. Salmons. 1996. The primacy of primary umlaut. Beiträge zur Geschichte der deutschen Sprache und Literatur $(P B B)$ 118. 69-86.

Jescheniak, Jörg. D. \& Willem J. M. Levelt. 1994. Word frequency effects in speech production: retrieval of syntactic information and of phonological form. Journal of Experimental Psychology: Learning, Memory, and Cognition 20(4). 824-843.

König, Werner. 1989. Atlas zur Aussprache des Schriftdeutschen in der Bundesrepublik Deutschland. Ismaening: Max Hueber Verlag.

Labov, William. 2001. Principles of linguistic change: Social factors. Malden and Oxford: Blackwell.

Lieberman, Erez, Jean-Baptiste Michel, Joe Jackson, Tina Tang \& Martin A. Nowak. 2007. Quantifying the evolutionary dynamics of language. Nature 449.7163. 713-716.

Mangold, Max. 1994. Duden Aussprachewörterbuch. Mannheim: Duden Verlag.

Moser, Hans, Hans Wellmann \& Norbert R. Wolf. 1988. Geschichte der deutschen Sprache III. Neuhochdeutsch. Stuttgart: UTB für Wissenschaft.

Phillips, Betty. 1984. Word frequency and the actuation of sound change. Language. 320-342.

Phillips, Betty. 2006. Word frequency and lexical diffusion. Hampshire and New York: Palgrave Macmillan.

Pierrehumbert, Janet. B. 2001. Exemplar dynamics: Word frequency, lenition and contrast. Typological Studies in Language 45. 137-158. 
Prince, Alan \& Paul Smolensky. 1993. Optimality Theory: constraint interaction in generative grammar. Rutgers University \& University of Colorado at Boulder. Published 2004, Oxford: Blackwell.

R Core Development Team. 2017. R: a language and environment for statistical computing. Vienna: R Foundation for Statistical Computing.

Sloos, Marjoleine. 2013a. Frequency and phonological grammar: An integrated approach. evidence from German, Indonesian, and Japanese. University of Groningen PhD dissertation.

Sloos, Marjoleine. 2013b. The reversal of the BÄREN-BEEREN merger in Austrian Standard German. The Mental Lexicon 8(3). 353-371.

Sloos, Marjoleine. 2018. Merger and reversal of the BÄrEN and BEEREN vowels: the role of salience. Studia Linguistica 72(2). 282-296.

Spiekermann, Helmut. 2008. Sprache in Baden-Württemberg: Merkmale des regionalen Standards. Tübingen: Max Niemeyer Verlag.

Tagliamonte, Sali. A. \& Harald Baayen. 2012. Models, forests and trees of York English: was/were variation as a case study for statistical practice. Language Variation and Change 24(2). 135-178.

Traunmüller, Hartmut. 1990. Analytical expressions for the tonotopic sensory scale. The Journal of the Acoustical Society of America 88(1). 97-100.

Tritschler, Artur. 1913. Zur Aussprache des Neuhochdeutschen im XVIII. Jahrhundert. Beiträge zur Geschichte der deutschen Sprache und Literatur (PBB) 1913.38. 373-458.

Viëtor, Wilhelm. 1909. Die Aussprache des Schriftdeutschen. Mit dem Wörterverzeichnis der amtlichen 'Regeln für die deusche Rechtschreibung in phonetischer Umschrift sowie phonetischen Texten'. Wien: Edition Praesens.

Voyles, Joseph. 1992. On Old High German i-umlaut. In Irmengard Rauch, Gerald F. Carr \& Robert L. Kyes (eds.), On Germanic Linguistics: Issues and Methods, 365-378. Berlin: Mouton De Gruyter.

Weijer, Jeroen van de. 1994. Segmental structure and complex segments. Leiden University PhD dissertation.

Weijer, Jeroen van de. 2012. Grammar as selection. Combining Optimality Theory and Exemplar Theory. Nagoya: Kougaku.

Weijer, Jeroen van de, Clemens Poppe \& Marjoleine Sloos. 2013. Family matters: Rendaku love and hatred. In J. van de Weijer \& T. Nishihara (eds.), Current issues in Japanese phonology: segmental variation in Japanese, 129-148. Tokyo: Kaitakusha.

Weijer, Jeroen van de. 2014. The origin of OT constraints. Lingua 142. 66-75. 
Wiese, Richard. 2000. The phonology of German. Paperback edition (original edition 1996). Oxford: Oxford University Press.

Wiesinger, Peter. 1970. Phonetisch-phonologische Untersuchungen zur Vokalentwicklung in den deutschen Dialekten I. Die Langvokale im Hochdeutschen. Berlin: Walter de Gruyter \& Co. 